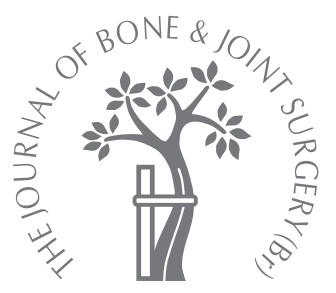

\title{
A lateral approach to the distal humerus following identification of the cutaneous branches of the radial nerve
}

\author{
D. Hannouche, \\ R. Ballis, \\ A. Raould, \\ R. S. Nizard, \\ A. C. Masquelet \\ From Hôpital \\ Lariboisière, Paris, \\ France
}

\footnotetext{
D. Hannouche, MD, PhD, Associate Professor

R. Ballis, MD, Resident

A. Raould, MD, Fellow

R. S. Nizard, MD, PhD,

Professor

Department of Orthopaedic

Surgery

Hôpital Lariboisière, 2 rue

Ambroise Paré, 75010 Paris,

France.

A. C. Masquelet, MD

Professor

Department of Orthopaedic

Surgery

Hôpital Avicenne 125 route de

Stalingrad, 93009 Bobigny,

France.

Correspondence should be sent to Professor D. Hannouche;

e-mail:

didier.hannouche@Irb.aphp.fr
}

(C)2009 British Editorial Society of Bone and Joint Surgery doi:10.1302/0301-620X.91B4. $21296 \$ 2.00$

$J$ Bone Joint Surg [Br] 2009;91-B:552-6.

Received 16 May 2008;

Accepted after revision 16

December 2008

\begin{abstract}
We describe a lateral approach to the distal humerus based on initial location of the superficial branches of the radial nerve, the inferior lateral cutaneous nerve of the arm and the posterior cutaneous nerve of the forearm. In 18 upper limbs the superficial branches of the radial nerve were located in the subcutaneous tissue between the triceps and brachioradialis muscles and dissected proximally to their origin from the radial nerve, exposing the shaft of the humerus. The inferior lateral cutaneous nerve of the arm arose from the radial nerve at the lower part of the spiral groove, at a mean of $14.2 \mathrm{~cm}$ proximal to the lateral epicondyle. The posterior cutaneous nerve of the forearm arose from the inferior lateral cutaneous nerve at a mean of $6.9 \mathrm{~cm}(6.0$ to 8.1$)$ proximal to the lateral epicondyle and descended vertically along the dorsal aspect of the forearm. The size and constant site of emergence between the triceps and brachioradialis muscles constitute a readily identifiable landmark to explore the radial nerve and expose the humeral shaft.
\end{abstract}

The identification and mobilisation of the radial nerve is recommended when plating fractures of the diaphysis of the humerus, ${ }^{1,2}$ for the removal of soft-tissue tumours of the lateral aspect of the arm, and in revision of total elbow replacements. ${ }^{3,4}$ Plating of the distal shaft of the humerus is commonly performed via a lateral approach, which may require inferior extension to gain distal exposure and to locate the radial nerve between the brachialis and brachioradialis muscles. ${ }^{5}$ Stabilisation is obtained by a compression plate that gives sufficient rigidity and stability at the fracture site to enable early mobilisation. ${ }^{1}$ The disadvantages of this approach are the need for extensive distal exposure to define the course of the radial nerve, the vulnerability of the radial nerve and its superficial branches when it pierces the lateral intermuscular septum, and the risk of iatrogenic denervation of the brachioradialis ${ }^{6}$ and brachialis muscles. ${ }^{7-9}$

We propose an alternative, strictly lateral approach based on the initial location of the lateral cutaneous branches of the radial nerve, namely the inferior lateral cutaneous nerve of the arm (ILCNA) and the posterior cutaneous nerve of the forearm (PCNF). These sensory nerves are large enough to be readily identified in the subcutaneous tissue at the lateral aspect of the arm between the triceps and brachioradialis muscles, and represent accurate practical landmarks for the dissection of the radial nerve. This approach should prove useful whenever surgical exploration of the radial nerve is required, especially in patients with nerve palsy ${ }^{10,11}$ and in a swollen or a scarred arm. It enables easy location of the nerve through both lateral and posterior skin incisions, and affords access to a large surface of the humeral shaft without jeopardising the nerve supply of the brachialis and brachioradialis muscles.

This anatomical study has examined the feasability of an alternative strictly lateral approach to the shaft of the humerus which allows exploration of the radial nerve and its superficial cutaneous ramifications.

\section{Materials and Methods}

The study was conducted on 18 upper limbs, nine right and nine left, from six embalmed and three fresh cadavers pre-injected with stained latex. The limbs were from six women and three men with a mean age of 75.4 years (69 to 83). Their mean height was $166 \mathrm{~cm}$ (162 to 176$)$.

All the fresh limbs underwent injection with a stain using the same technique, embalmed limbs were not injected. The axillary artery was dissected along its length and ligated below the inferior scapular pedicle. After flushing the artery with normal saline solution until peripheral venous distension was achieved, $50 \mathrm{ml}$ of latex solution 


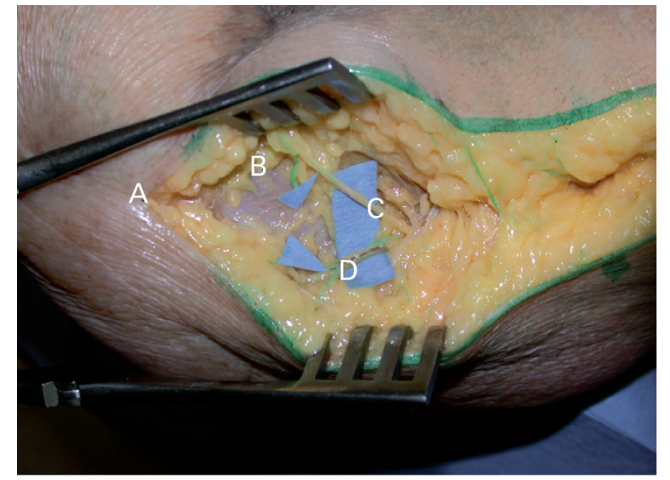

Fig. 1a

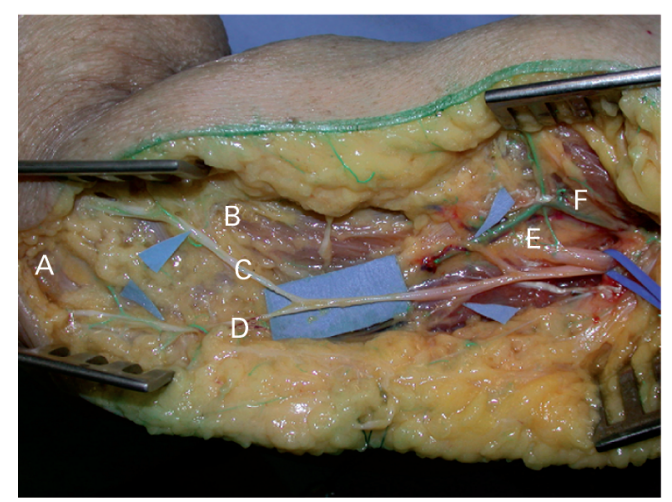

A: Lateral epicondyle

B: Brachioradialis muscle

C: Inferior lateral cutaneous

nerve of the arm

D: Posterior cutaneous nerve

of the forearm

E: Radial nerve

F: Deep brachial artery

Fig. $1 b$

Anatomical views of the left arm illustrating the proposed lateral approach based on initial location of the ILCNA (A) and the PCNF (B). The skin incision is straight and located $1 \mathrm{~cm}$ anterior to the intermuscular septum. (a) The distal sensory branches of the radial nerve (C) are identified between the brachioradialis (B) and triceps muscles, and then $\mathrm{b}$ ) dissected from distal to proximal to the radial nerve. The proximal dissection of these branches enables the exploration of the entire course of the radial nerve and exposure of the humeral shaft both anteriorly and posteriorly to the lateral intermuscular septum.

(Neoprene Latex 671, Dupont Ltd, United Kingdom), stained with eosin ( $2 \%$ aqueous eosin, $5 \mathrm{ml}$, Laboratoires Gilbert, Herouville Saint-Clair, France) or methylene blue (methylene blue, $2 \mathrm{ml}$, Gilbert) were injected manually under pressure.

The ramifications of the cutaneous branches of the radial nerve were defined first. The subjects were placed supine with the arm in slight abduction and internal rotation. The incision started proximally along the anterior border of the deltoid muscle and extended distally along the lateral aspect of the arm towards the lateral epicondyle, $1 \mathrm{~cm}$ anterior to the projection of the lateral intermuscular septum (Fig. 1a). The ILCNA and the PCNF were located in the subcutaneous tissue superficial to the brachial fascia and anterior to the lateral intermuscular septum, at a height corresponding to the upper part of the brachioradialis muscle (Fig. 1). The main cutaneous branches of the nerve crossed the skin incision. Once located, the branches were dissected proximally to establish their origin from the radial nerve and their relationships to the lateral intermuscular septum (Fig. 2). In its distal part the lateral intermuscular septum separates the medial head of the triceps from the brachioradialis muscle. Proximally, the lateral intermuscular septum separates the lateral head of the triceps from the brachialis muscle. The medial head of the triceps was progressively mobilised from distal to proximal. The radial nerve was exposed on the lateral surface of the humerus before it penetrated the lateral intermuscular septum. It was then dissected proximally to where it emerged from the spiral groove of the humerus. The shaft of the humerus was then approached on either side of the radial nerve, anterior and posterior to the lateral intermuscular septum.

The study analysed the number of superficial rami, their ramifications, and their relationships with the lateral intermuscular septum, the medial head of the triceps and the deep brachial artery. The distribution of each of the sensory branches was documented in a diagram. The 


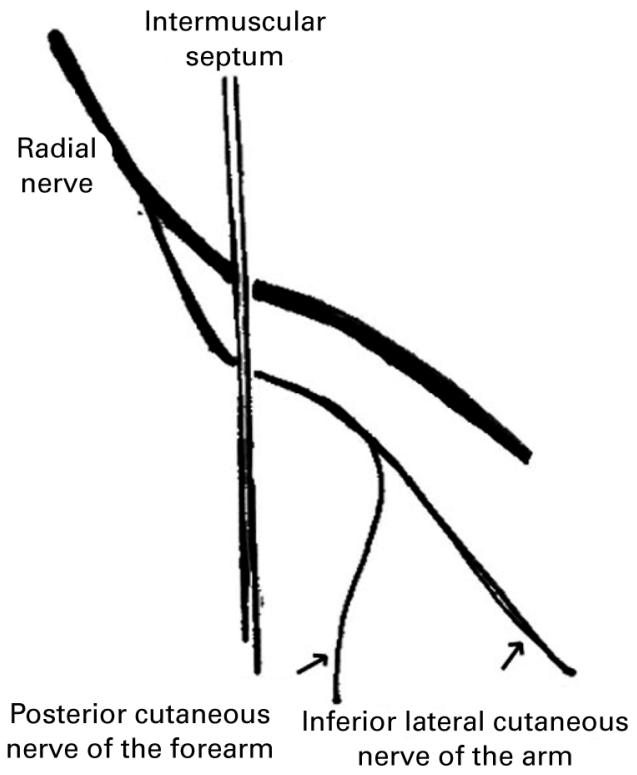

Fig. $2 a$

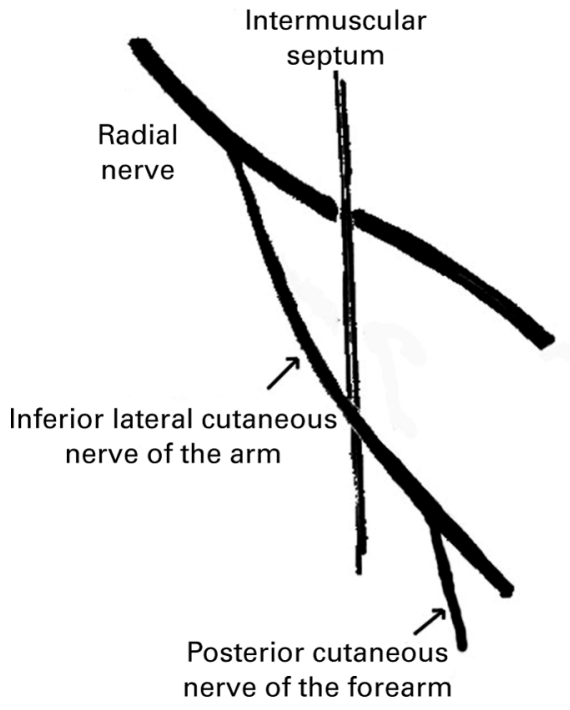

Fig. 2b

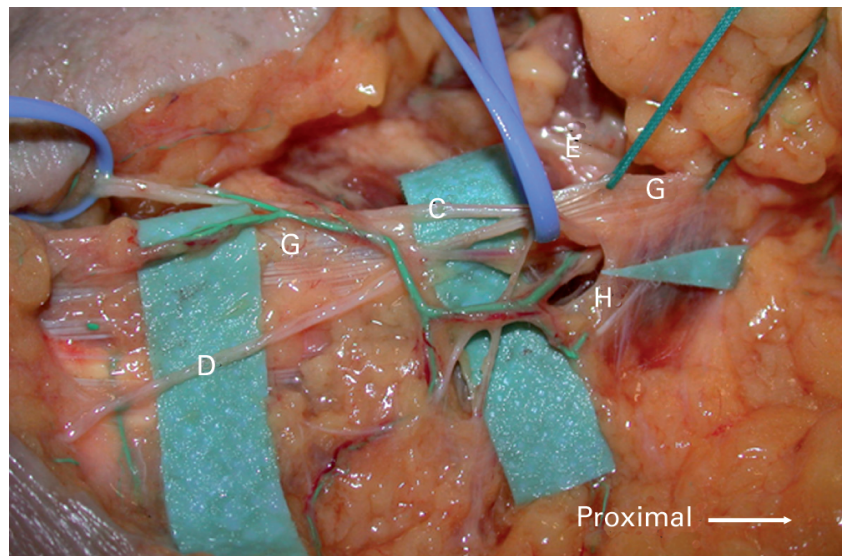

Fig. 2c

a) In three cases the ILCNA pierced the lateral intermuscular septum to penetrate the anterior compartment at a mean of $2.6 \mathrm{~cm}$ below the passage of the radial nerve into the anterior compartment. The PCNF (D) emerged in the anterior compartment. b) In 15 cases the ILCNA continued in the posterior compartment and emerged directly into the subcutaneous tissue after piercing the posterior brachial fascia. c) Lateral dissection of the left arm showing the ILCNA (C) piercing the posterior brachial fascia (H). The nerve is accompanied by the posterior branch of the deep brachial artery. (G) lateral intermuscular septum.

distances between the origins of those branches and the lateral epicondyle were measured.

\section{Results}

Anatomy of the inferior lateral cutaneous nerve of the arm. In all cases this nerve arose from the radial nerve at the inferior part of the spiral groove, usually on the lateral surface of the humerus, at a mean distance of $14.2 \mathrm{~cm}(13.5$ to 15.2) proximal to the lateral epicondyle and $4 \mathrm{~cm}(3.5$ to 5.0) proximal to the insertion of the highest fibres of the brachioradialis muscle. It then coursed distally along the external margin of the humerus and remained posterior to the lateral intermuscular septum until it emerged from the posterior compartment of the arm (Fig. 2). In three cases the nerve pierced the lateral intermuscular septum to enter the anterior compartment at a mean distance of $9.4 \mathrm{~cm}(6.2$ to 11.8$)$ proximal to the lateral epicondyle, which corresponded to a mean distance of $2.6 \mathrm{~cm}$ (1.4 to 3.9) below the passage of the radial nerve into the anterior compartment of the arm (Fig. 2a). The ILCNA perforated the anterior brachial fascia at a mean distance of $5.1 \mathrm{~cm}(4.0$ to 7.0$)$ (SD 1.2) proximal to the lateral epicondyle to travel 
superficially in the subcutaneous tissue. In 15 cases $(83 \%)$ it emerged directly from the posterior compartment into the subcutaneous tissue and perforated the posterior brachial fascia without penetrating the intermuscular septum (Figs $2 \mathrm{~b}, \mathrm{c})$. In all cases, the ILCNA ran superficially relative to the brachioradialis muscle, slightly anterior to its origin from the lateral column of the humerus, sending branches to the lateral surface of the distal part of the arm. During its proximal course in the posterior compartment, the nerve was accompanied by the posterior branch of the deep brachial artery, surrounded by its satellite veins (Fig. 1b).

Anatomy of the posterior cutaneous nerve of the forearm. In all cases the PCNF arose from the ILCNA. In 16 arms $(89 \%)$ the ILCNA gave rise to a single posterior sensory branch; in two cases $(11 \%)$ it split into two anterior rami of the same size and a posterior ramus. This division occurred at a mean of $6.9 \mathrm{~cm}(6.0$ to 8.1$)$ from the lateral epicondyle. In three cases $(17 \%)$ the PCNF arose from the anterior compartment of the arm, distal to the lateral intermuscular septum, at a mean of $3 \mathrm{~cm}$ after the ILCNA had perforated the septum (Fig. 2a). In the other 15 specimens (83\%), the PCNF arose in the posterior compartment of the arm and perforated the posterior brachial fascia. It descended in the subcutaneous tissue slightly anterior to the lateral intermuscular septum and passed anterior to the lateral epicondyle. In the distal part of the arm the PCNF ran backwards giving branches to the upper part of the posterolateral surface of the forearm.

Lateral approach to the shaft of the humerus. This study allowed the development of a strictly lateral exposure to the shaft of the humerus based on the initial identification of the distal sensory branches of the radial nerve between the brachioradialis and triceps muscles. These branches could be easily located at a predictable level on the lateral surface of the arm, and then dissected proximally to identify the radial nerve. The origin of the ILCNA was always sited at the inferior part of the spiral groove. The humerus was gained through a strictly lateral route without section of the brachialis muscle nor elevation of the brachioradialis. This approach enabled exploration of the radial nerve on either side of the lateral intermuscular septum at a very high level up to the spiral groove.

\section{Discussion}

The anterolateral approach to the shaft of the humerus is the most commonly performed. ${ }^{12-14}$ With this, the radial nerve is identified between the brachialis and brachioradialis muscles, and the distal two-thirds of the humerus can be exposed. However, dissection of the most distal aspect of the humerus in order to introduce a plate is difficult and requires extension into an anterior approach to the elbow. Proximal extension of this approach up to the spiral groove is possible, but injury to the ILCN may occur when separating the medial head of the triceps from the intermuscular septum. ${ }^{15}$ The extra-muscular branches of the radial nerve to the brachioradialis ${ }^{6}$ and to the bra- chialis muscles ${ }^{7-9,12}$ may be at risk when dissecting the space between brachialis and brachioradialis. Splitting the anterior aspect of brachialis may spare the supply from the radial nerve to this muscle, but may damage the lateral branches of the musculocutaneous nerve, which lie more superficially. ${ }^{8}$ Alternative approaches may be the medial ${ }^{16,17}$ and the posterior or posterolateral approaches, ${ }^{18-21}$ but both require the patient in the lateral decubitus or prone position with the affected extremity uppermost. Although preferred by some, ${ }^{22}$ the medial approach is more often recommended for the management of vascular injuries associated with fractures or complex nonunions of the shaft. ${ }^{23}$ The posterolateral exposures are useful for allowing the application of a centrally located posterior plate in treatment of fractures of the distal third of the humerus. ${ }^{19,21}$ This approach cannot be routinely recommended for more proximal fractures because of the proximity of the radial nerve, which may be subjected to traction during reduction and friction from the plate after surgery.

Several authors have proposed alternative lateral routes to gain maximal exposure of the radial nerve and the shaft. Moran ${ }^{15}$ described a posterolateral incision $4 \mathrm{~cm}$ behind the intermuscular septum which allowed control of the radial nerve on either side of the septum and stabilisation of the fracture with a posterior plate. Mills et $\mathrm{al}^{13}$ proposed a lateral approach similar to that described here, but through an incision $1 \mathrm{~cm}$ posterior to the septum and without dissection of the sensory branches of the radial nerve.

The strictly lateral exposure we present here is based on the initial identification of the ILCNA and the PCNF in the subcutaneous tissue and their proximal dissection to the radial nerve. The ILCNA provides the sensory innervation of the lateral surface of the distal third of the arm and is also known as the nerve of the lateral brachial flap. ${ }^{24}$ It always arises from the radial nerve at the lower extremity of the spiral groove posterior to the intermuscular septum, and may have a common origin with the nerve of the medial head of the triceps. ${ }^{25}$ It is $1 \mathrm{~mm}$ to $21 \mathrm{~mm}$ in diameter ${ }^{26}$ and emerges between the triceps and brachioradialis muscles, where it becomes superficial. It is easily identifiable and located along the lateral column of the humerus and at the highest of the fibres of the origin of the brachioradialis muscle. ${ }^{27-29}$ The PCNF is constant in its course. It emerges from the ILCNA, travels subcutaneously along the lateral column of the humerus, ${ }^{30}$ and descends vertically along the dorsal aspect of the forearm. When the skin incision is located $1 \mathrm{~cm}$ anterior to the intermuscular septum, the PCNF is located in the posterior lip of the wound. Proximal dissection of these branches enables the exploration of the entire course of the radial nerve and exposure of the humeral shaft, both anteriorly and posteriorly to the lateral intermuscular septum.

This approach allows exploration of any part of the radial nerve and reduces the risk of iatrogenic injury as it 
pierces the lateral intermuscular septum, where it is tethered and has very little mobility, as it is interposed between the lateral aspect of the humerus and the septum. ${ }^{25}$ The approach also allows rapid exposure of the radial nerve through a posterior skin incision with minimal soft-tissue stripping during revision of total elbow replacement and for the removal of soft-tissue tumours of the arm.

No benefits in any form have been received or will be received from a commercial party related directly or indirectly to the subject of this article.

\section{References}

1. DeFranco MJ, Lawton JN. Radial nerve injuries associated with humeral fractures. J Hand Surg [Am] 2006;31:655-63.

2. McCormack RG, Brien D, Buckley RE, et al. Fixation of fractures of the shaft of the humerus by dynamic compression plate or intramedullary nail: a prospective, randomised trial. J Bone Joint Surg [Br] 2000;82-B:336-9.

3. Goldberg SH, Cohen MS, Young M, et al. Thermal tissue damage caused by ultrasonic cement removal from the humerus. J Bone Joint Surg [Am] 2005;87-A:583-91.

4. Zook J, Ward WG Sr. Intraosseous radial nerve entrapment complicating total elbow revision. J Arthroplasty 2001;16:919-22.

5. Shao YC, Harwood P, Grotz MR, et al. Radial nerve palsy associated with fractures of the shaft of the humerus: a systematic review. J Bone Joint Surg [Br] 2005;87B:1647-52.

6. Latev MD, Dalley AF 2nd. Nerve supply of the brachioradialis muscle: surgically relevant variations of the extramuscular branches of the radial nerve. Clin Anat 2005;18:488-92.

7. Blackburn SC, Wood CP, Evans DJ, et al. Radial nerve contribution to brachialis in the UK Caucasian population: position is predictable based on surface landmarks. Clin Anat 2007;20:64-7.

8. Frazer EA, Hobson M, McDonald SW. The distribution of the radial and musculocutaneous nerves in the brachialis muscle. Clin Anat 2007;20:785-9.

9. Mahakkanukrauh P, Somsarp V. Dual innervation of the brachialis muscle. Clin Anat 2002;15:206-9.

10. Ekholm R, Adami J, Tidermark J, et al. Fractures of the shaft of the humerus: an epidemiological study of 401 fractures. J Bone Joint Surg [Br] 2006;88-B:1469-73.

11. Livani B, Belangero WD, Castro de Medeiros R. Fractures of the distal third of the humerus with palsy of the radial nerve: management using minimally-invasive percutaneous plate osteosynthesis. J Bone Joint Surg [Br] 206;88-B:1625-8.
12. Mekhail A0, Checroun AJ, Ebraheim A, et al. Extensile approach to the anterolateral surface of the humerus and the radial nerve. J Shoulder Elbow Surg 1999;8:112-18.

13. Mills WJ, Hanel DP, Smith DG. Lateral approach to the humeral shaft: an alternative approach for fracture treatment. J Orthop Trauma 1996;10:81-6.

14. Zlotolow DA, Catalano LW 3rd, Barron OA, Glickel SZ. Surgical exposures of the humerus. J Am Acad Orthop Surg 2006;14:754-65.

15. Moran MC. Modified lateral approach to the distal humerus for internal fixation. Clin Orthop 1997;340:190-7.

16. Bezes $\mathbf{H}$, Massart $\mathbf{P}$, Fourquet JP, et al. The value of combining multiple screwed plates in humeral shaft fractures. Int Orthop 1995;19:16-25 (in French).

17. Lancaster G, Kozin SH, Porter S. The medial surgical approach to the humerus. Tech Hand Up Extrem Surg 2000;4:201-6.

18. Bousquet $\mathbf{G}$, Colas $\mathbf{M}$, Chambat $\mathbf{P}$, Basconlerque $\mathbf{B}$. The posteromedial approach to fractures of the lower half of the humerus. Rev Chir Orthop Reparatrice Appar Mot 1977;63(Suppl 2):131-3 (in French).

19. Dabezies EJ, Banta CJ, Murphy CP, d'Ambrosio RD. Plate fixation of the humera shaft for acute fractures, with and without radial nerve injuries. J Orthop Trauma 1992;6:10-13.

20. Gerwin M, Robert NH, Andrew JW. Alternative operative exposures of the posterior aspect of the humeral diaphysis with reference to the radial nerve. J Bone Joint Surg [Br] 1996;78-B:1690-5.

21. Vander Griend R, Tomasin J, Ward EF. Open reduction and internal fixation of humeral shaft fractures: results using AO plating techniques. J Bone Joint Surg [Am] 1986;68-A:430-3

22. Laporte C, Jouve F, Jegou D, Saillart G. Medial approaches to the distal humerus for fracture fixation. Rev Chir Orthop Reparatrice Appar Mot 2002:88:177-81 (in French).

23. Jupiter JB. Complex non-union of the humeral diaphysis: treatment with a medial approach, an anterior plate, and a vascularized fibular graft. J Bone Joint Surg [Am] 1990;72-A:701-7

24. Rivet D, Buffet M, Martin D, et al. The lateral arm flap: an anatomic study. J Reconstr Microsurg 1987;3:121-32.

25. Carlan D, Pratt J, Patterson JM, et al. The radial nerve in the brachium: an anatomic study in human cadavers. J Hand Surg [Am] 2007;32:1177-82.

26. Bonnel F, Mansat M, Villa MA, et al. Anatomic and histological basis of surgery to the radial nerve. Anat Clin 1982;3:229-38.

27. Poirier P. Traité d'anatomie humain. In: Poirier P, ed. Vol 1. Paris: Masson, 1896:930-8.

28. Rouvière H. Anatomie humaine descriptive, topographique et fonctionnelle. In: Rouvière $\mathrm{H}$, ed. Vol 3. 13th edition. Paris: Masson, 1967:201-5.

29. Testut L. Traité d'anatomie humaine. In: Testut L, ed. Vol 1. Paris: Doin, 1949:298-306.

30. MacAvoy MC, Rust SS, Green DP. Anatomy of the posterior antebrachial cutaneous nerve: practical information for the surgeon operating on the lateral aspect of the elbow. J Hand Surg [Am]2006;31:908-11. 